\title{
Markov Chain Decomposition of Monthly Rainfall into Daily Rainfall: Evaluation of Climate Change Impact
}

\author{
Chulsang Yoo, Jinwook Lee, and Yonghun Ro \\ School of Civil, Environmental and Architectural Engineering, College of Engineering, Korea University, \\ Seoul 136-713, Republic of Korea
}

Correspondence should be addressed to Yonghun Ro; royh1@naver.com

Received 27 October 2015; Revised 4 April 2016; Accepted 7 April 2016

Academic Editor: Ji Chen

Copyright (C) 2016 Chulsang Yoo et al. This is an open access article distributed under the Creative Commons Attribution License, which permits unrestricted use, distribution, and reproduction in any medium, provided the original work is properly cited.

\begin{abstract}
This study evaluates the effect of climate change on daily rainfall, especially on the mean number of wet days and the mean rainfall intensity. Assuming that the mechanism of daily rainfall occurrences follows the first-order Markov chain model, the possible changes in the transition probabilities are estimated by considering the climate change scenarios. Also, the change of the stationary probabilities of wet and dry day occurrences and finally the change in the number of wet days are derived for the comparison of current $\left(1 \mathrm{x} \mathrm{CO}_{2}\right)$ and $2 \mathrm{x} \mathrm{CO}_{2}$ conditions. As a result of this study, the increase or decrease in the mean number of wet days was found to be not enough to explain all of the change in monthly rainfall amounts, so rainfall intensity should also be modified. The application to the Seoul weather station in Korea shows that about $30 \%$ of the total change in monthly rainfall amount can be explained by the change in the number of wet days and the remaining $70 \%$ by the change in the rainfall intensity. That is, as an effect of climate change, the increase in the rainfall intensity could be more significant than the increase in the wet days and, thus, the risk of flood will be much highly increased.
\end{abstract}

\section{Introduction}

To assess the impacts of climate change on regional or local water resources, hydrological modeling with hypothetical climate input has been used. Earlier studies may be classified into two categories: one which used the General Circulation Models (GCMs) to predict the impact of climate change [15] and the other that was based on hydrological simulations with assumed hypothetical input to demonstrate changes of various components of the hydrological cycle [6-10].

Many researchers in Korea also have a great interest in the effect of climate change on water resources, agriculture, fishing industry, forestry, and so forth [11-15]. All of their research has been aimed at the time when the $\mathrm{CO}_{2}$ concentration becomes doubled. They also considered several GCM predictions for their research, where somewhat sophisticated interpolation or multiple regression techniques were used to scale down the GCM predictions to small scale information. Especially in meteorology, Oh and Hong [16] reported that the rainfall amount would be increased by 10 to $15 \%$ annually and by up to $24 \%$ seasonally (about a $10 \%$ increase in spring,
$13 \%$ in summer, and $24 \%$ in fall and a slight decrease in winter). The annual mean temperature was also predicted to be increased by up to $3.5^{\circ} \mathrm{C}$. Their results were derived from a multiple regression analysis of three GCM predictions (CCC, UI, and GFDL GCM). Also, KAIST [17] analyzed five GCM predictions (GFDL-R30, CCC, GISS, UKMO, and GFDL GCM) to estimate the possible changes of annual rainfall amounts by $-5 \% \sim 25 \%$ and those for the monthly rainfall amounts by $-30 \% \sim 35 \%$ as a result of the $\mathrm{CO}_{2}$ doubling.

Ideally, the climate simulations using the GCM predictions could be used to derive the impact of climate change on regional or local water resources. However, this issue is totally complicated by the incompatibility of space scales between hydrological models and the GCMs. While the GCMs are invaluable tools for identifying the climate sensitivities and changes in global climate characteristics, their grid system is too coarse to assess the impact of climate change on major hydrological parameters such as soil water, evapotranspiration, and runoff on regional scales $[18,19]$. In addition, the GCM conceptualizations of atmospheric energy and moisture fluxes are limited by simplifications made in 
the parameterizations of cloud physics, energy transfer within the oceans, and land surface processes. Thus, some climate variables are better simulated than others. For example, mean air temperature is known to have higher precision than daily rainfall [20]. For this reason, the GCM outputs are interpreted as alternative climate scenarios rather than predictions [21].

Climate scenarios required for the assessment of water resources systems for the current condition $\left(1 \mathrm{x} \mathrm{CO}_{2}\right)$ are generally made using historic observations. If record length is limited, historic data are expanded using stochastic generation techniques [1, 20, 22-27]. Various statistical and stochastic characteristics are considered for the generation of the rainfall data. Examples are the wet and dry probabilities, the mean wet and dry periods, the mean number of wet days, the mean rainfall intensity, and so on. Similar factors are also considered for the generation of climate scenarios for $2 \mathrm{x} \mathrm{CO}_{2}$ condition.

As mentioned before, the GCM simulations are interpreted as alternative climate scenarios to be used as input data for generating input data for hydrological analysis. Generally, the GCM simulations are those averaged spatially over large areas as well as temporally over monthly to annual bases. As air temperature has relatively low variability and is also known to have higher confidence among GCM simulations, direct use of them may not cause any serious effect on hydrological simulations. However, precipitation is totally different. Not only are the GCM simulations of precipitation for the current climate condition notoriously poor, but also the veracity of predictions for future changes in precipitation is in serious question [28-30]. Even worse is that hydrological extremes (i.e., floods and droughts) are closely related to the space-time variability of precipitation rather than its spacetime average. As only the relative changes of precipitation amounts between GCM predictions of current and $2 \mathrm{x} \mathrm{CO}_{2}$ conditions are generally considered for the generation of precipitation data for $2 \mathrm{xCO}_{2}$ condition, it is practically impossible to derive, in a quantitative manner, the possible changes of precipitation characteristics.

The above considerations have motivated us to assess the possible changes of the precipitation characteristics. To accomplish this research objective, we chose the daily rainfall for further analysis. This is mainly because much longer and accurate data are available for the daily based rainfall than for the hourly or even shorter-time based rainfall. It is also considered that the Markov chain model is generally applied to be the daily data rather than the hourly data. That is, in this study the occurrence mechanism of daily rainfall is assumed to follow the first-order Markov chain model [31-34].

To evaluate the impact of climate change on daily rainfall using the Markov chain model, we began by investigating the historic measurements of daily rainfall to quantify the transition characteristics between wet and dry days depending on the monthly rainfall amount. This is basically to estimate the changes of the transition probabilities of wet to wet, wet to dry, dry to wet, and dry to dry conditions due to the climate change. Also, climate change should be quantified as the changes of monthly rainfall amount, which are nothing but various GCM predictions for the condition of $2 \mathrm{x} \mathrm{CO}_{2}$. With estimated transition probabilities for the condition of
$2 \mathrm{x} \mathrm{CO}_{2}$, we can also estimate the change in the number of wet days. Finally, the change in the number of wet days will lead us to know what the rainfall intensity should be. By comparing the number of wet days and the rainfall intensities for the $1 \mathrm{x} \mathrm{CO}_{2}$ and $2 \mathrm{xCO}_{2}$ conditions, we may get some idea about how differently the patterns of flood or drought would be changed. That is, this study will lead us to know more detailed information about the rainfall pattern due to the climate change.

\section{A Markov Chain Model for Daily Rainfall Occurrence}

The daily rainfall model based on a Markov chain decides rainfall occurrence (i.e., the wet or dry conditions) based on transition probabilities [31-35]. The transition probabilities, estimated from the historic measurements, represent the probabilities of wet to wet, wet to dry, dry to wet, and dry to dry conditions. If the next day is wet, then the rainfall intensity is given as a random variable following a probability density function. Exponential, Gamma, and mixed Gamma distributions are commonly used [36].

The daily rainfall model, based on the Markov chain, has several advantages. Easy parameter estimation and easy data generation are probably the most obvious advantages which make the Markov chain model more popular than the Poisson process model. Poisson process models have more complex structures as well as more difficulties in parameter estimation [37-40].

The daily rainfall model based on the Markov chain can be explained as follows. First, define $X_{t}$ as the wet or dry condition at the $t$ th day. That is,

$$
\begin{aligned}
& X_{t}=0, \quad \text { if day } t \text { is dry, } \\
& X_{t}=1, \quad \text { if day } t \text { is wet. }
\end{aligned}
$$

Also, the daily rainfall time series $Y_{t}$ can be made by multiplying the rainfall intensity $R_{t}$ by $X_{t}$ such as

$$
Y_{t}=R_{t} X_{t}
$$

Thus, $Y_{t}$ becomes zero when $X_{t}$ is zero (no rain or dry) and $Y_{t}$ becomes $R_{t}$ when $X_{t}$ is one. Assuming that the occurrence probability of rainfall at present is dependent on the condition of the previous day, then $X_{t}$ follows the first-order Markov chain, and then the transition probability of daily rainfall can be divided into the following four cases:

$$
\begin{aligned}
& P\left[X_{t}=1 \mid X_{t-1}=0\right]=p_{01} \\
& P\left[X_{t}=1 \mid X_{t-1}=1\right]=p_{11} \\
& P\left[X_{t}=0 \mid X_{t-1}=0\right]=p_{00} \\
& P\left[X_{t}=0 \mid X_{t-1}=1\right]=p_{10} .
\end{aligned}
$$

The above equations express the conditional probabilities of wet or dry on day $t$ depending on the condition of wet or dry on day $t-1$. Therefore $p_{00}=1-p_{01}$ and $p_{11}=$ 
$1-p_{10}$. Also, these four probabilities constitute a transition probability matrix:

$$
P_{T}=\left(\begin{array}{ll}
p_{00} & p_{01} \\
p_{10} & p_{11}
\end{array}\right)
$$

The transition probability matrix in (4), however, may not clearly quantify the characteristics of daily rainfall, especially when comparing the $1 \mathrm{x} \mathrm{CO}_{2}$ and $2 \mathrm{x} \mathrm{CO}_{2}$ conditions. This is because the possible change of the transition probability would be so small that no more than a $10 \%$ difference may be expected, even applying rather extreme GCM predictions for the $2 \mathrm{x} \mathrm{CO}_{2}$ condition. Thus, we need a better statistic for comparing the $1 \mathrm{xCO}_{2}$ and $2 \mathrm{xCO}_{2}$ conditions.

A good statistic in this case may be the number of wet days, which is not only practical but also easier to compare. To derive the number of wet days, we first need to define the $n$-step transition probabilities:

$$
P_{T}^{n}=\left(\begin{array}{ll}
p_{00} & p_{01} \\
p_{10} & p_{11}
\end{array}\right)^{n}
$$

The $n$-step transition probabilities converge to certain probabilities as $n$ increases:

$$
\lim _{n \rightarrow \infty} P_{T}^{n}=\lim _{n \rightarrow \infty}\left(\begin{array}{ll}
p_{00} & p_{01} \\
p_{10} & p_{11}
\end{array}\right)^{n}=\left(\begin{array}{ll}
p_{0} & p_{1} \\
p_{0} & p_{1}
\end{array}\right) .
$$

These probabilities, $p_{0}$ and $p_{1}$, are unique characteristics of a given system [41], which, in this case, represent the mean occurrence probabilities of dry and wet days, respectively. These are called the stationary probabilities or the extreme probabilities. Also, the inverse of these stationary probabilities represents the mean return period of dry and wet days; thus the multiplication of these stationary probabilities by the total number of days in a given month indicates the average number of dry and wet days, respectively.

\section{Data Characteristics}

3.1. Data. The data used in this study are the daily precipitation records obtained from the Seoul weather station. The Seoul weather station, as shown in Figure 1, is located in Seoul, Korea. Seoul is the capital city of Korea. It is located at the $37^{\circ} 34^{\prime}$ north latitude and the $126^{\circ} 57^{\prime}$ east longitude. Seoul receives an average annual precipitation of $1,370.5 \mathrm{~mm}$. As Korea is located in the monsoon region of Far Eastern Asia, it receives more than $70 \%$ of its annual rainfall during wet summer season from June to September.

The Seoul weather station has more than 100 years of daily rainfall record, of which we selected the data collected during the period between 1960 and 2014 for the analysis. This data period was selected as the data after 1960 have been well quality-controlled. These data are provided by the Korean Meteorological Administration (KMA). Figure 2 shows a typical pattern of rainfall seasonality in Far Eastern Asia.

3.2. Basic Statistics. Table 1 summarizes the monthly means, standard deviations, and the lag-one (day) autocorrelation

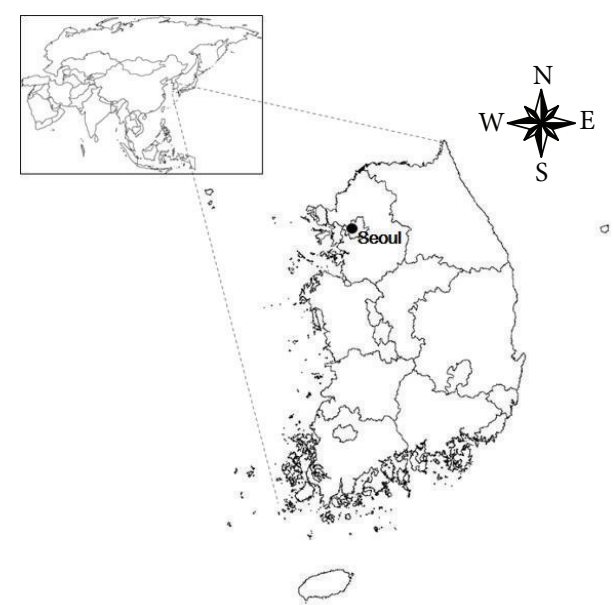

(Kilometers)

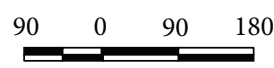

FIGURE 1: The location of Seoul weather station, Korea.

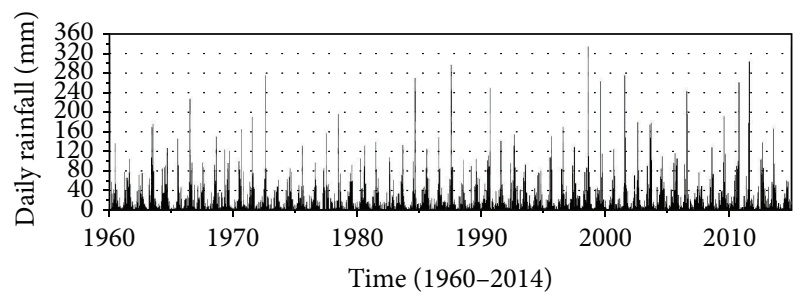

FIgURE 2: Daily rainfall data collected at the Seoul weather station, Korea.

coefficients of daily rainfall along with the monthly mean number of wet days. First thing to be noticed from this table is the strong seasonality of monthly rainfall. Large rainfall amounts as well as large numbers of wet days during the summer (from June to September) are common characteristics in the Asian monsoon region. The lag-1 (day) correlation coefficients are also statistically significant, even though they are still at a low level around 0.1. The lag2 (day) correlation coefficients are found to be statistically insignificant for all months. This weak correlation structure of daily rainfall enables us to adopt the Markov chain model for further analysis.

\subsection{Transition Probability versus Monthly Rainfall Amount.} As can be seen from Figure 3, the monthly transition probabilities are closely related with the monthly rainfall amounts. That is, the larger the monthly rainfall amounts, the larger the wet to wet probabilities but the smaller the dry to dry probabilities. As the sum of the wet to wet probability and the wet to dry probability for a given month should equal one, the wet to dry probability decreases as the rainfall amount increases. Similarly, the dry to wet probability increases as the rainfall amount increases. Table 2 summarizes the regression curves of transition probabilities estimated monthly as functions of monthly rainfall amounts. 
TABLE 1: Monthly statistics of daily rainfall at the Seoul weather station.

\begin{tabular}{|c|c|c|c|c|}
\hline Month & $\begin{array}{c}\text { Mean } \\
(\mathrm{mm} / \text { day })\end{array}$ & $\begin{array}{l}\text { Standard deviation } \\
(\mathrm{mm} / \text { day })\end{array}$ & $\begin{array}{c}\text { Lag-1 (day) } \\
\text { autocorrelation } \\
\text { coefficient }\end{array}$ & $\begin{array}{l}\text { Monthly mean } \\
\text { number of wet days }\end{array}$ \\
\hline January & 0.6 & 0.6 & 0.08 & 6.5 \\
\hline February & 0.9 & 1.1 & 0.06 & 5.8 \\
\hline March & 1.4 & 1.0 & -0.01 & 7.0 \\
\hline April & 2.8 & 2.3 & 0.07 & 8.4 \\
\hline May & 3.2 & 1.9 & 0.05 & 8.6 \\
\hline June & 4.6 & 3.6 & 0.07 & 10.3 \\
\hline July & 12.9 & 6.7 & 0.08 & 16.5 \\
\hline August & 10.5 & 7.1 & 0.14 & 14.4 \\
\hline September & 5.4 & 4.6 & 0.07 & 9.2 \\
\hline October & 1.6 & 1.4 & 0.04 & 6.2 \\
\hline November & 1.7 & 1.1 & 0.06 & 9.2 \\
\hline December & 0.7 & 0.6 & 0.01 & 7.3 \\
\hline
\end{tabular}
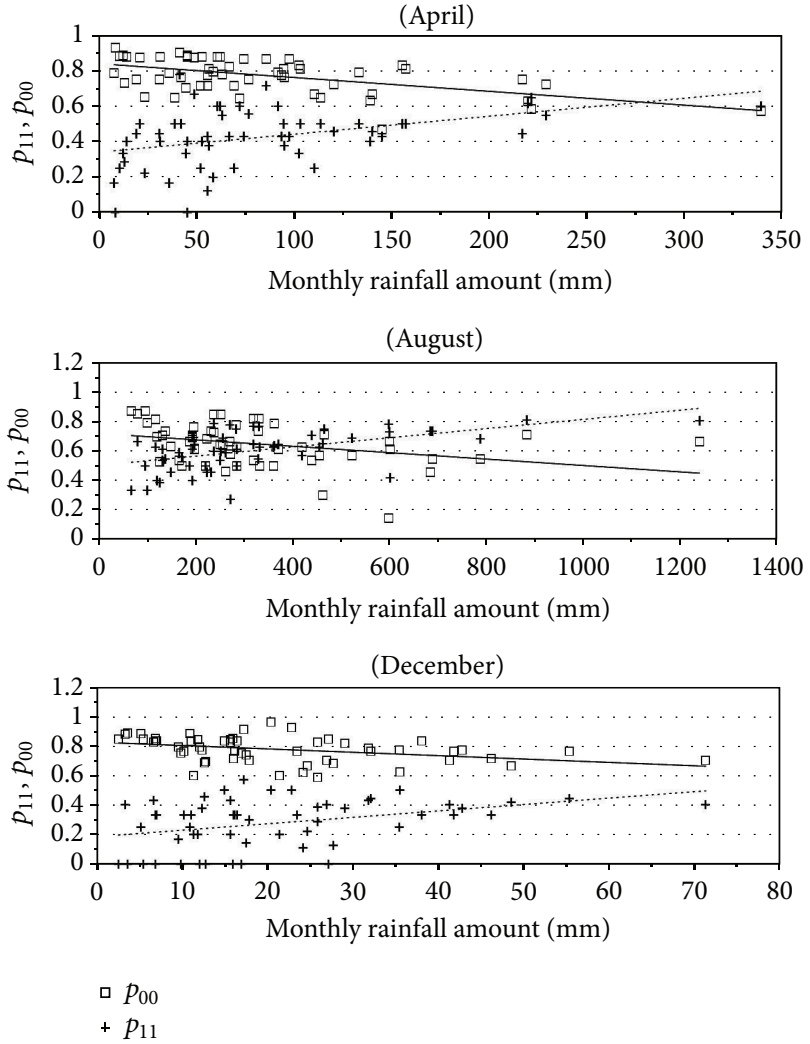

FIGURE 3: Sample regression lines of transition probabilities $p_{11}$ and $p_{00}$ estimated with respect to monthly rainfall amounts.

The parameters of the regression curves do not show any seasonal trends, but the months with large rainfall amounts have smaller slopes than those with small rainfall amounts. In fact, the steep slope seems to be due to rather severe rainfall events during the given month. For example, in July, one or two severe rainfall events generally occurred along with several minor events; thus the slope can be steep. On the other
TABLE 2: Regression curves of transition probabilities $\left(p_{11}\right.$ and $\left.p_{00}\right)$ estimated with respect to the monthly rainfall amounts $\left(P_{i}\right)$.

\begin{tabular}{lcccc}
\hline \multirow{2}{*}{ Month } & \multicolumn{2}{c}{$p_{11}=a \times P_{i}+b$} & \multicolumn{2}{c}{$p_{00}=a \times P_{i}+b$} \\
& $a$ & $b$ & $a$ & $b$ \\
\hline January & 0.00399 & 0.20249 & -0.00222 & 0.85330 \\
February & 0.00451 & 0.19002 & -0.00189 & 0.87203 \\
March & 0.00164 & 0.24153 & -0.00118 & 0.85416 \\
April & 0.00101 & 0.33920 & -0.00078 & 0.83505 \\
May & 0.00139 & 0.25798 & -0.00074 & 0.84442 \\
June & 0.00077 & 0.35661 & -0.00052 & 0.79667 \\
July & 0.00023 & 0.56941 & -0.00037 & 0.75317 \\
August & 0.00031 & 0.50144 & -0.00022 & 0.71956 \\
September & 0.00085 & 0.28804 & -0.00016 & 0.78929 \\
October & 0.00193 & 0.23835 & -0.00046 & 0.85601 \\
November & 0.00288 & 0.21762 & -0.00154 & 0.79568 \\
December & 0.00435 & 0.18519 & -0.00228 & 0.82526 \\
\hline
\end{tabular}

hand, only minor rainfall events occurred in May; thus the slope becomes rather mild. The coefficients of determination also show no obvious seasonal trend, but those for the dry to dry probabilities were higher than those for the wet to wet probabilities. Even though estimates of the coefficient of determination $\left(R^{2}\right)$ are mostly around 0.2-0.4, all of them are found to be statistically significant. These rather small $R^{2}$ values seem to be from the natural variability of rainfall process. However, as can be found in Figure 3, the trend is obvious. Even though the values themselves are rather small, they are all significant and, we believe, they are all meaningful.

\section{Climate Change Effect on Daily Rainfall}

4.1. Climate Change Scenarios. The Intergovernmental Panel on Climate Change (IPCC) has been releasing the evaluation report on the climate change every five or six years. Most recent report has been released in 2013 (5th report), 
TABLE 3: List of models used for the analysis.

\begin{tabular}{|c|c|c|}
\hline Model name & Modeling center (or group) & Institute ID \\
\hline BCC-CSM1.1 & Beijing Climate Center, China Meteorological Administration & BCC \\
\hline BCC-CSM1.1 (m) & Beijing Climate Center, China Meteorological Administration & BCC \\
\hline CCSM4 & National Center for Atmospheric Research & NCAR \\
\hline CESM1 (CAM5) & Community Earth System Model Contributors & NSF-DOE-NCAR \\
\hline CSIRO-Mk3.6.0 & $\begin{array}{l}\text { Commonwealth Scientific and Industrial Research Organization in } \\
\text { collaboration with Queensland Climate Change Centre of Excellence }\end{array}$ & CSIRO-QCCCE \\
\hline FIO-ESM & The First Institute of Oceanography, SOA, China & FIO \\
\hline GFDL-CM3 & NOAA Geophysical Fluid Dynamics Laboratory & NOAA GFDL \\
\hline GFDL-ESM2M & NOAA Geophysical Fluid Dynamics Laboratory & NOAA GFDL \\
\hline GISS-E2-H & NASA Goddard Institute for Space Studies & NASA GISS \\
\hline GISS-E2-R & NASA Goddard Institute for Space Studies & NASA GISS \\
\hline IPSL-CM5A-MR & Institute Pierre-Simon Laplace & IPSL \\
\hline MIROC5 & $\begin{array}{l}\text { Japan Agency for Marine-Earth Science and Technology, Atmosphere and } \\
\text { Ocean Research Institute (The University of Tokyo), and National Institute for } \\
\text { Environmental Studies }\end{array}$ & MIROC \\
\hline MIROC-ESM-CHEM & $\begin{array}{l}\text { Japan Agency for Marine-Earth Science and Technology, Atmosphere and } \\
\text { Ocean Research Institute (The University of Tokyo), and National Institute for } \\
\text { Environmental Studies }\end{array}$ & MIROC \\
\hline MIROC-ESM & $\begin{array}{l}\text { Japan Agency for Marine-Earth Science and Technology, Atmosphere and } \\
\text { Ocean Research Institute (The University of Tokyo), and National Institute for } \\
\text { Environmental Studies }\end{array}$ & MIROC \\
\hline MRI-CGCM3 & Meteorological Research Institute & MRI \\
\hline NorESM1-M & Norwegian Climate Centre & NCC \\
\hline
\end{tabular}

where new emission scenarios of greenhouse gases, the Representative Concentration Pathways (RCP), have been adopted instead of the previous Special Report on Emission Scenario (SRES). The RCP scenarios were made to consider the recent changes of greenhouse gas concentration as well as its temporal change.

In the RCP scenarios, the concentration change of greenhouse gases was quantified by the extra radiation forcing with the same unit of solar radiation. Each RCP scenario was made to consider the path to reach the extra radiation forcing in the target year of 2100. A total of four RCP scenarios were considered in the IPCC report 2013, which are extra radiation forcing $2.6,4.5,6.0$, and $8.5 \mathrm{~W} / \mathrm{m}^{2}$ in the year of 2100. The RCP scenarios were also named to be RCP2.6, RCP4.5, RCP6.0, and RCP8.5 by considering these extra radiation forcing. As the solar radiation is about $238 \mathrm{~W} / \mathrm{m}^{2}$, the RCP8.5 scenario indicates that the total radiation is to be increased by $3.6 \%(=8.5 / 238)$ in the target year of 2100 . The RCP8.5 represents the fact that the current trend of greenhouse gas increase remains unchanged. Other scenarios were made to consider the possible decrease in the emission of greenhouse gases.

The $\mathrm{CO}_{2}$ concentration has been increased by about $40 \%$ since the industrial evolution around 1670 . The $\mathrm{CO}_{2}$ concentration is about $391 \mathrm{ppm}$ as of the year 2011. Assuming that the $\mathrm{CO}_{2}$ concentration in the year of 2011 is $1 \mathrm{x} \mathrm{CO}_{2}$ condition, only the RCP8.5 scenario provides the $2 \mathrm{x} \mathrm{CO}_{2}$ condition before the year of 2100 . The $\mathrm{CO}_{2}$ concentration will be about $792 \mathrm{ppm}$ in the year of 2084 [42].
This study used the information provided at the Climate Change Knowledge Portal (CCKP) by the World Bank. Wide variety of data regarding the climate change can be found in the CCKP. Prediction results by GCMs on the possible change of temperature and precipitation (with the $0.5^{\circ}$ by $0.5^{\circ}$ spatial resolution) based on the RCP scenarios of the 5th IPCC reports can also be obtained from 2020 to 2099. The GCMs used for the prediction are called the CCKP-collection, which are composed of a total of 16 models (Table 3). These prediction results are those obtained at the CMIP5 (the fifth phase of the Climate Model Intercomparison Project) [43].

The prediction results used in this study are summarized in Table 4 . These results are those for the period 4 (20802099) based on the RCP8.5 scenario, which contains the year of 2084 when the $\mathrm{CO}_{2}$ concentration will be doubled $\left(2 \mathrm{x} \mathrm{CO}_{2}\right.$ condition). In this study, instead of applying the GCM predictions directly to the regression curves of transition probability (Table 2), we summarized the sixteen GCM predictions of monthly rainfall by their average, minimum, and maximum after excluding highest and lowest predictions (Table 4). This was to exclude extreme predictions compared to others. Use of average, minimum, and maximum predictions instead of each of the 16 predictions was to consider the uncertainty of GCM predictions and also to provide a possible range of changes in daily rainfall characteristics.

Table 4 shows that the monthly rainfall is expected to be increased a bit in most months. The rainfall increase is concentrated, especially, in the months of January, February, March, May, June, August, and October. As June and August 
TABLE 4: Changes (represented by ratios of the $2 \mathrm{x} \mathrm{CO}_{2}$ condition with respect to the $1 \mathrm{x} \mathrm{CO}_{2}$ condition) of monthly rainfall amounts predicted by several GCMs (average, minimum, and maximum values were decided after excluding the lowest and highest predictions each month).

\begin{tabular}{|c|c|c|c|c|c|c|c|c|c|c|c|c|c|}
\hline \multirow{2}{*}{ GCM } & \multicolumn{13}{|c|}{ Month } \\
\hline & Jan & Feb & Mar & Apr & May & Jun & Jul & Aug & Sep & Oct & Nov & Dec & Annual \\
\hline BCC-CSM1.1 & 0.6 & 2.1 & 1.3 & 0.8 & 1.3 & 1.5 & 0.9 & 1.1 & 0.9 & 0.9 & 0.9 & 0.5 & 1.06 \\
\hline BCC-CSM1.1 (m) & 0.9 & 1.0 & 0.7 & 0.7 & 1.4 & 1.3 & 0.9 & 1.2 & 1.4 & 0.7 & 0.7 & 0.8 & 1.07 \\
\hline CCSM4 & 1.0 & 1.5 & 1.5 & 0.9 & 0.9 & 1.3 & 0.9 & 1.1 & 1.2 & 1.3 & 1.0 & 0.9 & 1.08 \\
\hline CESM1 (CAM5) & 1.3 & 1.7 & 1.2 & 0.9 & 1.1 & 1.4 & 1.1 & 1.2 & 1.3 & 1.2 & 0.9 & 0.8 & 1.17 \\
\hline CSIRO-Mk3.6.0 & 1.5 & 1.4 & 1.5 & 0.8 & 1.1 & 1.1 & 1.0 & 1.2 & 1.1 & 0.5 & 1.1 & 1.7 & 1.10 \\
\hline FIO-ESM & 0.9 & 0.7 & 0.6 & 0.8 & 1.4 & 1.3 & 0.8 & 1.1 & 0.9 & 0.7 & 1.0 & 0.3 & 0.98 \\
\hline GFDL-CM3 & 2.7 & 1.0 & 1.4 & 0.8 & 1.3 & 1.3 & 1.0 & 1.4 & 0.9 & 0.9 & 0.1 & 0.6 & 1.12 \\
\hline GFDL-ESM2M & 0.7 & 0.5 & 1.0 & 0.9 & 1.3 & 1.1 & 0.9 & 1.0 & 1.0 & 1.1 & 0.7 & 0.6 & 0.98 \\
\hline GISS-E2-H & 1.3 & 1.2 & 1.5 & 0.9 & 1.1 & 1.2 & 1.0 & 1.2 & 0.8 & 0.6 & 0.7 & 1.3 & 1.03 \\
\hline GISS-E2-R & 0.7 & 1.7 & 1.6 & 1.2 & 1.1 & 1.2 & 0.9 & 1.1 & 0.8 & 0.9 & 1.0 & 1.7 & 1.05 \\
\hline IPSL-CM5A-MR & 1.4 & 1.6 & 2.2 & 1.5 & 1.4 & 1.4 & 0.9 & 0.8 & 0.6 & 0.6 & 0.3 & 0.6 & 0.98 \\
\hline MIROC5 & 1.4 & 1.8 & 1.8 & 1.3 & 1.1 & 1.6 & 0.7 & 0.9 & 0.8 & 1.7 & 0.9 & 1.2 & 1.03 \\
\hline MIROC-ESM-CHEM & 1.3 & 1.5 & 1.7 & 1.1 & 1.5 & 1.5 & 0.9 & 1.1 & 1.0 & 1.3 & 1.0 & 1.2 & 1.14 \\
\hline MIROC-ESM & 1.3 & 1.6 & 0.8 & 1.3 & 1.3 & 2.1 & 1.0 & 1.1 & 1.3 & 1.9 & 1.4 & 0.9 & 1.25 \\
\hline MRI-CGCM3 & 0.8 & 1.4 & 1.4 & 1.2 & 1.2 & 1.2 & 1.0 & 1.3 & 1.0 & 1.0 & 1.3 & 0.9 & 1.13 \\
\hline NorESM1-M & 1.0 & 0.8 & 0.8 & 1.1 & 1.2 & 1.3 & 1.1 & 1.2 & 1.2 & 1.5 & 0.8 & 0.8 & 1.14 \\
\hline Average & 1.10 & 1.35 & 1.30 & 0.99 & 1.24 & 1.34 & 0.95 & 1.14 & 1.00 & 1.03 & 0.88 & 0.90 & 1.05 \\
\hline $\begin{array}{l}\text { (minimum- } \\
\text { maximum) }\end{array}$ & $\begin{array}{c}(0.7- \\
1.5)\end{array}$ & $\begin{array}{c}(0.7- \\
1.8)\end{array}$ & $\begin{array}{c}(0.7- \\
1.8)\end{array}$ & $\begin{array}{c}(0.8- \\
1.3)\end{array}$ & $\begin{array}{l}(1.1- \\
1.4)\end{array}$ & $\begin{array}{l}(1.1- \\
1.6)\end{array}$ & $\begin{array}{c}(0.8- \\
1.1)\end{array}$ & $\begin{array}{c}(0.9- \\
1.3)\end{array}$ & $\begin{array}{c}(0.8- \\
1.3)\end{array}$ & $\begin{array}{c}(0.6- \\
1.7)\end{array}$ & $\begin{array}{c}(0.3- \\
1.3)\end{array}$ & $\begin{array}{c}(0.5- \\
1.7)\end{array}$ & $\begin{array}{c}(0.94- \\
1.16)\end{array}$ \\
\hline
\end{tabular}

are included in the wet season in Korea, the flood risk during these months could be increased. On the other hand, the risk of spring drought in Korea may be alleviated due to the increase of rain during March and May. However, as GCM predictions are so widely distributed from decrease to increase, it is not easy to conclude any obvious increase or decrease of the monthly rainfall in the future due to the doubling of $\mathrm{CO}_{2}$ gas concentration.

4.2. Effect of Climate Change on Daily Rainfall. The first step to quantify the climate change effect on the daily rainfall characteristics was to estimate the transition probabilities. The change in the transition probabilities was estimated using the regression curves and also by considering the change of monthly rainfall amounts. After estimating all the transition probabilities, the stationary probabilities of wet and dry days were calculated based on (6). Finally, by multiplying the stationary probabilities for wet and dry days by the total number of days in a given month, the number of wet and dry days could be estimated. The general framework of this study to evaluate the impact of climate change is given in Figure 4.

Figure 5 compares the transition probabilities estimated for the current state and the average, minimum, and maximum of sixteen GCM predictions for the $2 \mathrm{x} \mathrm{CO}_{2}$ condition. Also, Figure 6 compares the stationary probabilities of wet and dry days and the number of wet days. As only minor changes were made in the transition probabilities and in the stationary probabilities, the number of wet days would be a better characteristic to compare.

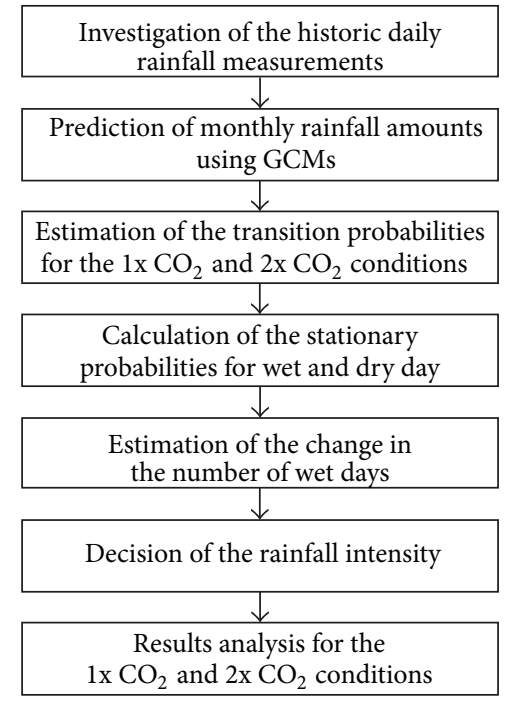

Figure 4: General framework of this study.

Quite interestingly, for most months, less than two days increase or decrease in the number of wet days is expected even for the months with a 70\% increase of monthly rainfall amount. Even when applying the maximum predictions among sixteen GCMs, only February, March, May, June, and December are expected to have more than one day increase in the number of wet days. Comparing more than $50 \%$ increases 


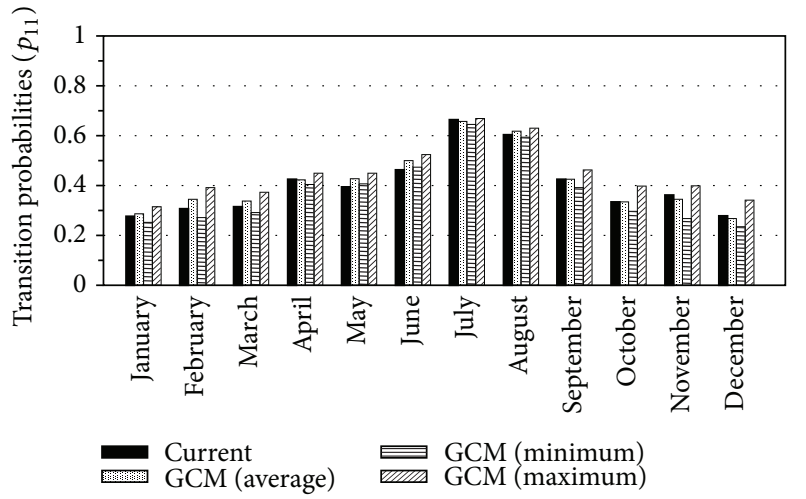

(a) $p_{11}$

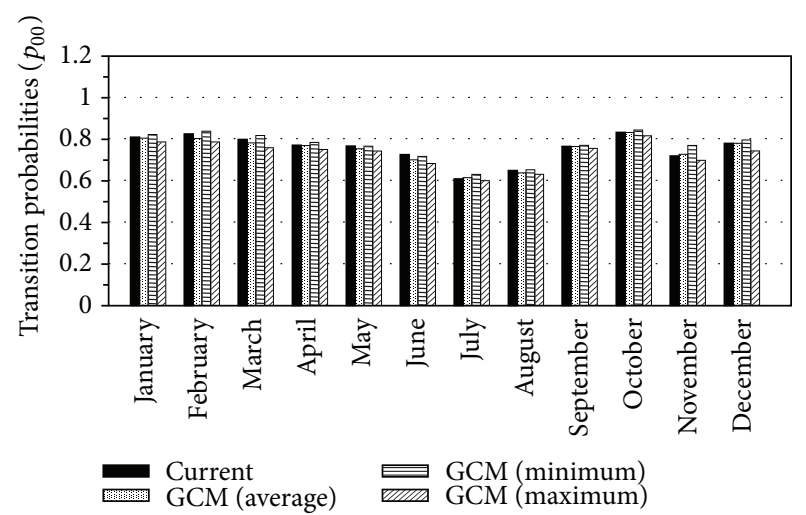

(b) $p_{00}$

FIgURE 5: Transition probabilities $p_{11}$ and $p_{00}$ of current $\left(1 \mathrm{x} \mathrm{CO}_{2}\right)$ and $2 \mathrm{x} \mathrm{CO}_{2}$ (GCM average, minimum, and maximum) conditions.

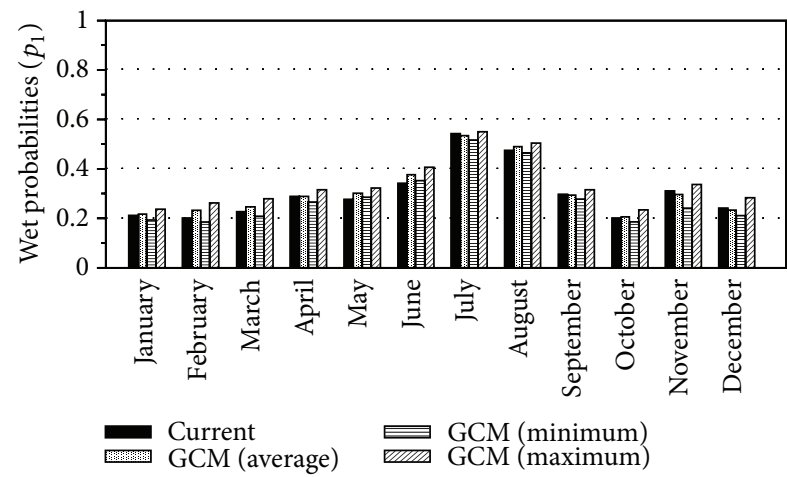

(a) $p_{1}$

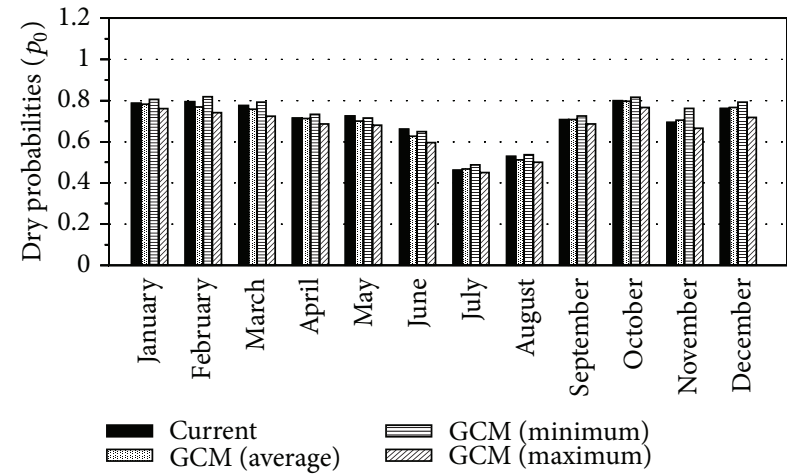

(b) $p_{0}$

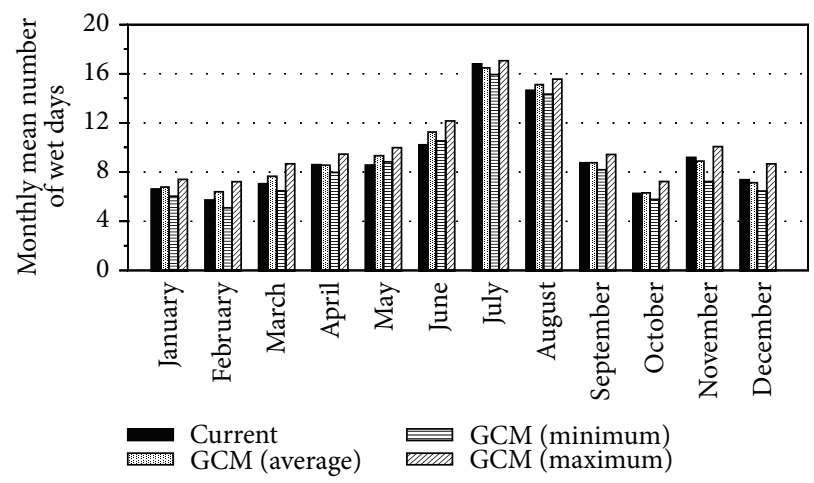

(c) N_wet

Figure 6: Wet probabilities $\left(p_{1}\right)$, dry probabilities $\left(p_{0}\right)$, and monthly mean numbers of wet days $\left(\mathrm{N}_{-}\right.$wet $)$of current $\left(1 \mathrm{x} \mathrm{CO}_{2}\right)$ and $2 \mathrm{x} \mathrm{CO}_{2}$ (GCM average, minimum, and maximum) conditions.

in the rainfall amounts, the estimated increases in the number of wet days are rather small.

As can be seen from Figure 6, the increase or decrease in the number of wet days is not enough to explain all the changes in the monthly rainfall amounts. Thus, the remaining portion has to be explained by the change in the rainfall intensity. That is, if the number of wet days is increased by $10 \%$, the rainfall amount can be increased by $10 \%$ without any increase in the rainfall intensity. However, if the increase of the number of wet days is limited to $5 \%$, then the remaining $5 \%$ has to be supplemented by the increase in the rainfall intensity.

In this way, we could divide the change in the monthly rainfall amounts into the change in the number of wet days and the change in the rainfall intensity (Table 5). As can be found in Table 5, the change in the number of wet days is biggest in May (40\%) and smallest in October (16\%). On the other hand, the change in the rainfall intensity is biggest 
TABLE 5: Division of the change of monthly rainfall amounts (C_R) into the change of the mean number of wet days (C_N) and the change of the mean daily rainfall intensity $\left(C_{-} I\right)$.

\begin{tabular}{|c|c|c|c|c|c|c|c|c|}
\hline State & Month & $\mathrm{C} \_\mathrm{R}$ & $\mathrm{C} \_\mathrm{N}$ & C_I & Month & C_R & $\mathrm{C} \_\mathrm{N}$ & C_I \\
\hline Current & \multirow{4}{*}{ January } & - & - & - & \multirow{4}{*}{ July } & - & - & - \\
\hline GCM (Avg) & & 0.10 & $0.03(27 \%)$ & $0.07(73 \%)$ & & -0.05 & $-0.02(30 \%)$ & $-0.04(70 \%)$ \\
\hline GCM (Min) & & -0.33 & $-0.09(27 \%)$ & $-0.24(73 \%)$ & & -0.16 & $-0.05(30 \%)$ & $-0.11(70 \%)$ \\
\hline GCM (Max) & & 0.47 & $0.13(28 \%)$ & $0.34(72 \%)$ & & 0.05 & $0.02(30 \%)$ & $0.04(70 \%)$ \\
\hline Current & \multirow{4}{*}{ February } & - & - & - & \multirow{4}{*}{ August } & - & - & - \\
\hline GCM (Avg) & & 0.35 & $0.13(36 \%)$ & $0.23(64 \%)$ & & 0.14 & $0.03(25 \%)$ & $0.11(75 \%)$ \\
\hline GCM (Min) & & -0.29 & $-0.10(34 \%)$ & $-0.19(66 \%)$ & & -0.07 & $-0.02(24 \%)$ & $-0.06(76 \%)$ \\
\hline GCM (Max) & & 0.75 & $0.28(37 \%)$ & $0.47(63 \%)$ & & 0.26 & $0.06(25 \%)$ & $0.19(75 \%)$ \\
\hline Current & \multirow{4}{*}{ March } & - & - & - & \multirow{4}{*}{ September } & - & - & - \\
\hline GCM (Avg) & & 0.30 & $0.09(29 \%)$ & $0.22(71 \%)$ & & 0.00 & $0.00(22 \%)$ & $0.00(78 \%)$ \\
\hline GCM (Min) & & -0.32 & $-0.09(29 \%)$ & $-0.23(71 \%)$ & & -0.24 & $-0.06(24 \%)$ & $-0.18(76 \%)$ \\
\hline GCM (Max) & & 0.78 & $0.23(30 \%)$ & $0.55(70 \%)$ & & 0.29 & $0.07(26 \%)$ & $0.22(74 \%)$ \\
\hline Current & \multirow{4}{*}{ April } & - & - & - & \multirow{4}{*}{ October } & - & - & - \\
\hline GCM (Avg) & & -0.01 & $0.00(30 \%)$ & $-0.01(70 \%)$ & & 0.03 & $0.01(16 \%)$ & $0.03(84 \%)$ \\
\hline GCM (Min) & & -0.24 & $-0.07(30 \%)$ & $-0.17(70 \%)$ & & -0.38 & $-0.08(22 \%)$ & $-0.30(78 \%)$ \\
\hline GCM (Max) & & 0.31 & $0.09(31 \%)$ & $0.21(69 \%)$ & & 0.69 & $0.16(23 \%)$ & $0.53(77 \%)$ \\
\hline Current & \multirow{4}{*}{ May } & - & - & - & \multirow{4}{*}{ November } & - & - & - \\
\hline GCM (Avg) & & 0.24 & $0.10(40 \%)$ & $0.14(60 \%)$ & & -0.12 & $-0.04(35 \%)$ & $-0.08(65 \%)$ \\
\hline GCM (Min) & & 0.08 & $0.03(40 \%)$ & $0.05(60 \%)$ & & -0.66 & $-0.22(33 \%)$ & $-0.44(67 \%)$ \\
\hline GCM (Max) & & 0.40 & $0.16(41 \%)$ & $0.24(59 \%)$ & & 0.25 & $0.09(35 \%)$ & $0.16(65 \%)$ \\
\hline Current & \multirow{4}{*}{ June } & - & - & - & \multirow{4}{*}{ December } & - & - & - \\
\hline GCM (Avg) & & 0.34 & $0.10(31 \%)$ & $0.23(69 \%)$ & & -0.10 & $-0.03(26 \%)$ & $-0.07(74 \%)$ \\
\hline GCM (Min) & & 0.10 & $0.03(30 \%)$ & $0.07(70 \%)$ & & -0.47 & $-0.12(26 \%)$ & $-0.35(74 \%)$ \\
\hline GCM (Max) & & 0.60 & $0.19(31 \%)$ & $0.41(69 \%)$ & & 0.67 & $0.18(27 \%)$ & $0.49(73 \%)$ \\
\hline
\end{tabular}

in October (80\%) and smallest in May (60\%). It is obvious that the change in the number of wet days and the change in the rainfall intensity are complementary to each other. Summarizing the results, about $30 \%$ of the total change of monthly rainfall amount is explained by the change in the number of wet days and the remaining $70 \%$ by the change in the rainfall intensity.

\section{Summary and Conclusions}

This study evaluated the effects of climate change on daily rainfall, especially on the mean number of wet days and the mean rainfall intensity. We assumed that the mechanism of rainfall occurrences follows the first-order Markov chain model. We also investigated the historic measurements of daily rainfall to find strong relations between the monthly rainfall amounts and the transition probabilities between wet and dry days. Using these relations, we could estimate the changes in the transition probabilities of wet to wet, wet to dry, dry to wet, and dry to dry conditions due to the climate change represented by the changes of monthly rainfall amounts. The changes in monthly rainfall amounts used in this study were those predicted by several GCMs for the condition of $2 \mathrm{x} \mathrm{CO}_{2}$ summarized by their averages, minimums, and maximums. With estimated transition probabilities, we estimated the change in the stationary probabilities of wet and dry conditions and, finally, the change in the number of wet days.

As an example application to the Seoul weather station in Korea, the transition probabilities and the stationary probabilities of wet and dry days for both $1 \mathrm{x} \mathrm{CO} \mathrm{CO}_{2}$ and $2 \mathrm{x}$ $\mathrm{CO}_{2}$ conditions were estimated. However, the differences between the two conditions were too small to be used to assess global warming effect numerically as well as practically in hydrology. Better and more obvious differences were found in the comparison of the number of wet days. For most months, less than two days increase or decrease in the number of wet days was estimated, even for the months with a $70 \%$ increase in the monthly rainfall amount. Only February, March, May, June, and December were found to have more than one day increases in the number of wet days even when applying the maximum predictions among sixteen GCMs. Comparing more than $50 \%$ increases in the rainfall amounts, the estimated increases in the number of wet days are rather small.

Investigation of the change in the number of wet days shows that the increase or decrease in the number of wet days was not enough to explain all the changes of monthly rainfall amounts; thus rainfall intensity should also be modified. The application to the Seoul weather station shows that about $30 \%$ 
of the total change of monthly rainfall amount was explained by the change in the number of wet days and the remaining $70 \%$ by the change in the rainfall intensity.

\section{Competing Interests}

The authors declare that they have no competing interests.

\section{Acknowledgments}

This research was supported by a grant (14AWMP-B08256401) from Advanced Water Management Research Program funded by Ministry of Land, Infrastructure and Transport of Korean Government. The authors also acknowledge the World Climate Research Programme's Working Group on Coupled Modelling, which is responsible for CMIP, and they also would like to thank the climate modeling groups (listed in Table 3 of this paper) for producing and making available their model output. For CMIP, the US Department of Energy's Program for Climate Model Diagnosis and Intercomparison provided coordinating support and led development of software infrastructure in partnership with the Global Organization for Earth System Science Portals.

\section{References}

[1] G. J. McCabe Jr. and M. A. Ayers, "Hydrologic effects of climate change in the Delaware River basin," Water Resources Bulletin, vol. 25, no. 6, pp. 1231-1242, 1989.

[2] F. H. S. Chiew, P. H. Whetton, T. A. McMahon, and A. B. Pittock, "Simulation of the impacts of climate change on runoff and soil moisture in Australian catchments," Journal of Hydrology, vol. 167, no. 1-4, pp. 121-147, 1995.

[3] G. J. McCabe and L. E. Hay, "Hydrological effects of hypothetical climate change in the East River basin, Colorado, USA," Hydrological Sciences Journal, vol. 40, no. 3, pp. 303-318, 1995.

[4] B. Nijssen, G. M. O'Donnell, A. F. Hamlet, and D. P. Lettenmaier, "Hydrologic sensitivity of global rivers to climate change," Climatic Change, vol. 50, no. 1-2, pp. 143-175, 2001.

[5] N. S. Christensen, A. W. Wood, N. Voisin, D. P. Lettenmaier, and R. N. Palmer, "The effects of climate change on the hydrology and water resources of the Colorado River basin," Climatic Change, vol. 62, no. 1-3, pp. 337-363, 2004.

[6] J. Nemec and J. Schaake, "Sensitivity of water resource systems to climate variation," Hydrological Sciences Journal, vol. 27, no. 3, pp. 327-343, 1982.

[7] L. L. Nash and P. H. Gleick, "Sensitivity of streamflow in the Colorado Basin to climatic changes," Journal of Hydrology, vol. 125, no. 3-4, pp. 221-241, 1991.

[8] M. Sanderson and J. Smith, "Climate change and water in the Grand River, Ontario," in Proceedings of the 43rd Annual Conference of the Canadian Water Resources Association, pp. 243-261, Penticton, Canada, May 1990.

[9] P. Singh and L. Bengtsson, "Hydrological sensitivity of a large Himalayan basin to climate change," Hydrological Processes, vol. 18, no. 13, pp. 2363-2385, 2004.

[10] R. N. Jones, F. H. S. Chiew, W. C. Boughton, and L. Zhang, "Estimating the sensitivity of mean annual runoff to climate change using selected hydrological models," Advances in Water Resources, vol. 29, no. 10, pp. 1419-1429, 2006.
[11] J. H. Oh, "Climate change due to $\mathrm{CO}_{2}$ increase: prediction of precipitation change in Korea," in Proceedings of the Effect of Climate Change on Korea, Korea Institute of Science and Technology (KIST '93), pp. 37-112, 1993.

[12] S. Kim and H. Kim, Studies on Potential Effects of Climate Change on Korea and Strategic Measures for the Global Environment (Water Resources Division), Department of Science and Technology, Korea, 1995.

[13] S. N. Oh, Research and Development on Technology for Global Environmental Monitoring and Climate Change Prediction, Department of Environment, Korea, 1995.

[14] C.-H. Chung, "Vegetation response to climate change on Jeju Island, South Korea, during the last deglaciation based on pollen record," Geosciences Journal, vol. 11, no. 2, pp. 147-155, 2007.

[15] S. Jung, S. Ha, and H. Na, "Multi-decadal changes in fish communities Jeju island in relation to climate change," Korean Journal of Fisheries and Aquatic Sciences, vol. 46, no. 2, pp. 186194, 2013.

[16] J. H. Oh and S. G. Hong, "Precipitation change in Korea due to atmospheric $\mathrm{CO}_{2}$ increase," Journal of Korea Water Resources Association, vol. 28, no. 3, pp. 143-157, 1995 (Korean).

[17] Korea Advanced Institute of Science Technology, Climate Change Impact Assessment and Development of Visualization Techniques for Climate Information, Ministry of Environment, 1995 (Korean).

[18] P. H. Gleick, "Methods for evaluating the regional hydrologic impacts of global climatic changes," Journal of Hydrology, vol. 88, no. 1-2, pp. 97-116, 1986.

[19] J. Schmidli, C. Frei, and P. L. Vidale, "Downscaling from GCM precipitation: a benchmark for dynamical and statistical downscaling methods,' International Journal of Climatology, vol. 26, no. 5, pp. 679-689, 2006.

[20] R. B. Wardlaw, M. Hulme, and A. Y. Stuck, "Modelling the impacts of climatic change on water resources," Water and Environment Journal, vol. 10, no. 5, pp. 355-364, 1996.

[21] D. P. Lettenmaier and T. Y. Gan, "Hydrologic sensitivities of the Sacromento-San Joaquin river basin, California, to global warming," Water Resources Research, vol. 26, no. 1, pp. 69-86, 1990.

[22] C. W. Richardson, "Stochastic simulation of daily precipitation, temperature, and solar radiation," Water Resources Research, vol. 17, no. 1, pp. 182-190, 1981.

[23] D. P. Lettenmaier and D. P. Sheer, "Climatic sensitivity of California water resources," Journal of Water Resources Planning and Management, vol. 117, no. 1, pp. 108-125, 1991.

[24] H. Y. F. Ng and J. Marsalek, "Sensitivity of streamflow simulation to changes in climate inputs," Nordic Hydrology, vol. 23, no. 4, pp. 257-272, 1992.

[25] M. A. Semenov and E. M. Barrow, "Use of a stochastic weather generator in the development of climate change scenarios," Climatic Change, vol. 35, no. 4, pp. 397-414, 1997.

[26] T. I. Harrold, A. Sharma, and S. J. Sheather, "A nonparametric model for stochastic generation of daily rainfall occurrence," Water Resources Research, vol. 39, no. 10, 2003.

[27] R. Mehrotra and A. Sharma, "A semi-parametric model for stochastic generation of multi-site daily rainfall exhibiting lowfrequency variability," Journal of Hydrology, vol. 335, no. 1-2, pp. 180-193, 2007.

[28] S. L. Grotch, "Regional intercomparisons of general circulation model predictions and historical data," Technical Note 
DOE/NBB0084, U.S. Department of Energy, Washington, DC, USA, 1988.

[29] D. Rind, R. Goldberg, and R. Ruedy, "Change in climate variability in the 21st century," Climatic Change, vol. 14, no. 1, pp. 5-37, 1989.

[30] E. F. Wood, D. P. Lettenmaier, and J. R. Wallis, "Comparison of an alternative land surface parameterization with the GFDL high resolution climate model," in Hydrological Interactions Between Atmosphere, Soil, and Vegetation, IAHS Publications no. 204, pp. 53-64, 1991.

[31] R. W. Katz, "Precipitation as a chain-dependent process," Journal of Applied Meteorology, vol. 16, no. 7, pp. 671-676, 1977.

[32] P. Todorovic and D. A. Woolhiser, "A stochastic model of n-day precipitation," Journal of Applied Meteorology, vol. 14, no. 1, pp. 17-24, 1975.

[33] R. D. Stern and R. Coe, "A model fitting analysis of daily rainfall data," Journal of the Royal Statistical Society Series A, vol. 147, no. 1, pp. 1-34, 1984.

[34] J. T. Schoof and S. C. Pryor, "On the proper order of Markov chain model for daily precipitation occurrence in the contiguous United States," Journal of Applied Meteorology and Climatology, vol. 47, no. 9, pp. 2477-2486, 2008.

[35] E. Waymire and V. K. Gupta, "The mathematical structure of rainfall representations: 1 . A review of the stochastic rainfall models," Water Resources Research, vol. 17, no. 5, pp. 1261-1272, 1981.

[36] D. S. Wilks, "Multisite generalization of a daily stochastic precipitation generation model," Journal of Hydrology, vol. 210, no. 1-4, pp. 178-191, 1998.

[37] D. Entekhabi, I. Rodriguez-Iturbe, and P. S. Eagleson, "Probabilistic representation of the temporal rainfall by a modified Neymann-Scott rectangular pulses model: parameter estimation and validation," Water Resources Research, vol. 25, no. 2, pp. 295-302, 1989.

[38] I. Rodriguez-Iturbe, V. K. Gupta, and E. Waymire, "Scale considerations in the modeling of temporal rainfall," Water Resources Research, vol. 20, no. 11, pp. 1611-1619, 1984.

[39] I. Rodriguez-Iturbe, D. R. Cox, and V. Isham, "Some models for rainfall based on stochastic point processes," Proceedings of the Royal Society of London A: Mathematical, Physical and Engineering Sciences, vol. 410, no. 1839, pp. 269-288, 1987.

[40] I. Rodriguez-Iturbe, D. R. Cox, and V. Isham, "A point process model for rainfall: further developments," Proceedings of the Royal Society of London A: Mathematical, Physical and Engineering Sciences, vol. 417, no. 1853, pp. 283-298, 1988.

[41] E. Parzen, Stochastic Processes, Holden-Day Series in Probability and Statistics, Holden-Day, San Francisco, Calif, USA, 1962.

[42] M. Meinshausen, S. J. Smith, K. Calvin et al., "The RCP greenhouse gas concentrations and their extensions from 1765 to 2300," Climatic Change, vol. 109, no. 1, pp. 213-241, 2011.

[43] K. E. Taylor, R. J. Stouffer, and G. A. Meehl, "An overview of CMIP5 and the experiment design," Bulletin of the American Meteorological Society, vol. 93, no. 4, pp. 485-498, 2012. 

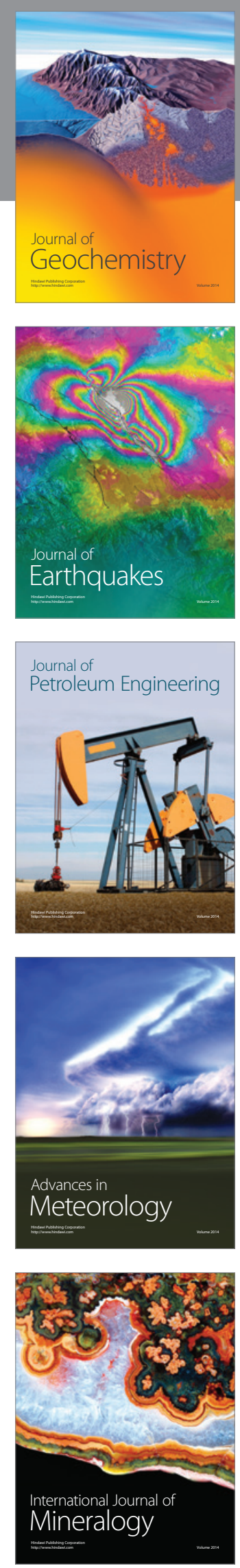
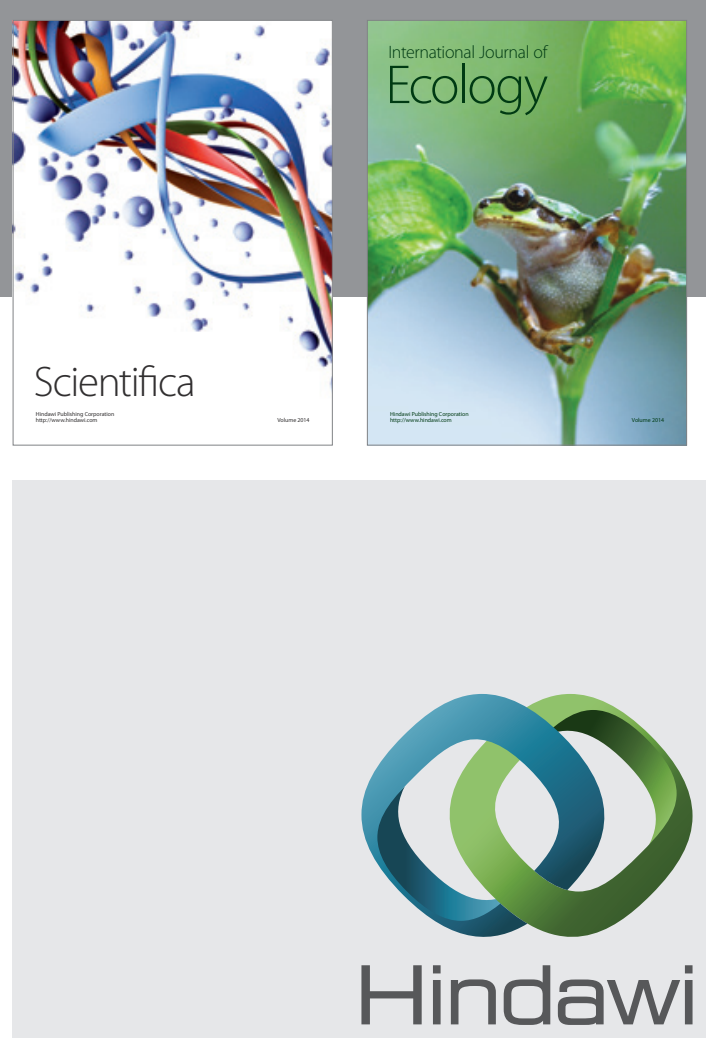

Submit your manuscripts at

http://www.hindawi.com
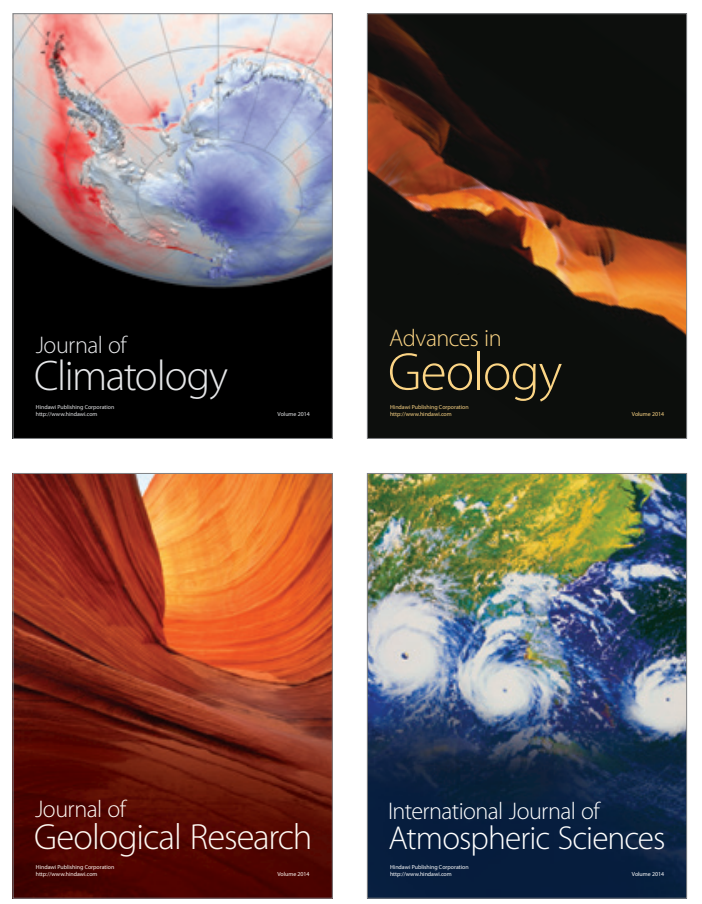

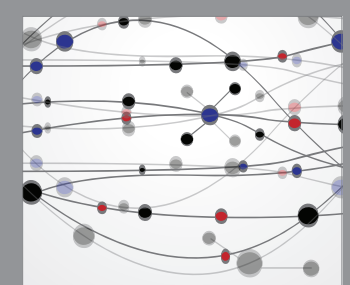

The Scientific

\section{World Journal}
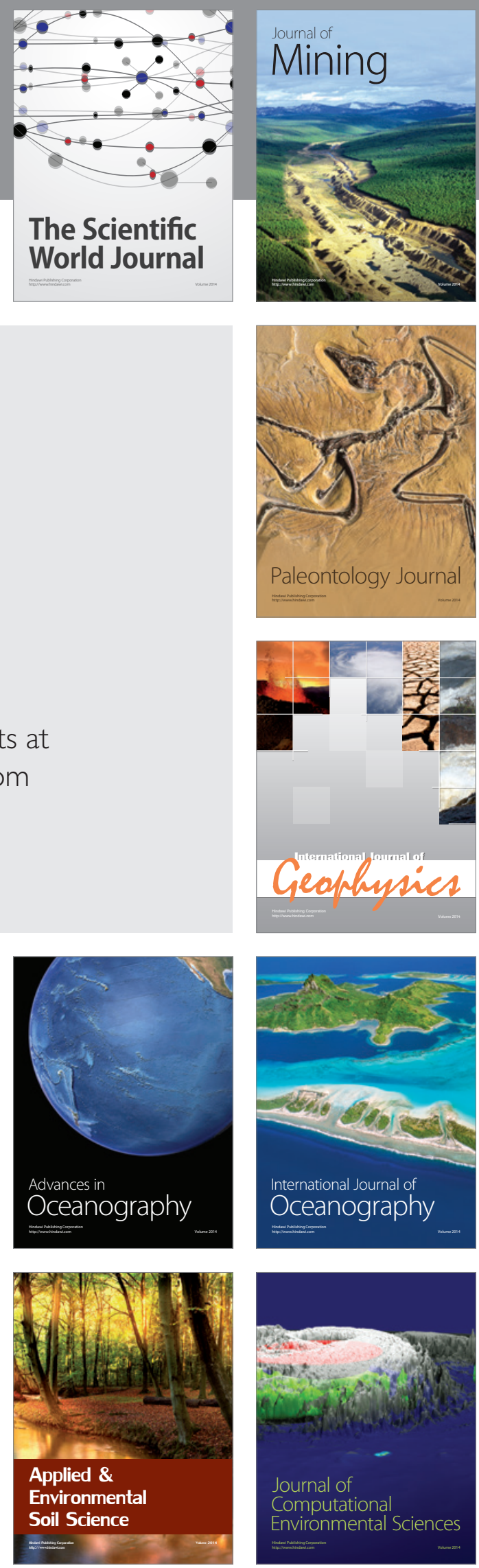